\title{
THE THIRD SCIENCE REVOLUTION AND ITS POSSIBLE CONSEQUENCES IN ARCHAEOLOGY
}

\section{A Personal Reflection}

Stefan Larsson

National Historical Museums

Odlarevägen 5, 22660 Lund, Sweden

stefan.larsson@shmm.se

I must confess to not being exactly certain about what Kristian Kristiansen is aiming at. Perhaps the article should be read as an expression of the joy of life, in these "most exciting of times" as Kristian Kristiansen puts it. And that is not a bad thing. We can do with an occasional reminder of how exciting archaeology can be, being bogged down in applications for funding or struggling inside the planning system. The article caused me to stop, sit down and make some reflections.

Are the times for archaeology exciting? Possibly, considering all the advances in science, the rapid development in computer technology and the massive expansion of archaeological data, both quantitative and qualitative, now being made available through an increased number of publications. The latter is somewhat of a flood, making it difficult to keep tabs even within one's own limited field of archaeology.

Unfortunately, the times for archaeology are also exciting in a more worrying way, with increasing difficulties and limitations following in the wake of the commodification of archaeology and cultural heritage.

Making forecasts is always difficult, especially if we have the feeling of being in the midst of a change. There is an inherent possibility of exaggerating the importance of the present situation, which I suppose is only human. Kristian Kristiansen is wondering about, and arguing for, a possible new paradigm within archaeology. Whether he perceives this as driven by recent theoretical trends or what he calls the third science 
revolution in archaeology is somewhat unclear to me. It probably does not matter, and is more related to me than to Kristian Kristiansen. I, somewhat resignedly, think we are in some kind of constant flow. Ideally it is the nature of archaeology with an ongoing dialectic between an ever-increasing amount of produced data, readjusted theoretical standpoints and questions, and methodological and technical possibilities.

As with the phenomena we are dedicated to study, changes within archaeology, or I might say "archaeologies", are of different tempo and duration, follow a variety of trajectories and are of different magnitude related to what kind of "needs" they can fulfil. When the dust has somewhat settled we stand with additional interesting perspectives to try out empirically and methodically. This makes it difficult, even with hindsight, to make out distinctive turning points, when and exactly with what text or lecture did post-processual archaeology start? As Kristian Kristiansen points out, elements of processual (“New Archaeology") have been maintained and developed during the reign of post-processual archaeology, while they also, together with elements of the latter will remain either independently or integrated in this (rather exciting) "return of the artefact"/"neo-material turn" we now can see.

A large proportion of what is ascribed to shifts of paradigms is usually produced through positioning within academia. In the varying practices of field archaeology the approaches tend to be more eclectic, applying what proves to be operational in the circumstances.

Does this mean that I disagree with Kristian Kristiansen? Not at all, since there obviously is an epistemological change going on. Whether this is the outcome of a general conscious or subconscious fatigue from the last decades of neo-liberal and post-modern mayhem or in fact based on the advances within science is open for discussion. Kristian Kristiansen mentions both, but in the end appears to lean towards the latter. Needless to say, the relationships between technical and methodological developments are complex and translated (in an ANT sense) along different and changing trajectories. We often get infatuated by the potential possibilities before sitting down and think about how to utilize it. I spent a lot of the r99os being frustrated about the conceptual muddling of technical development being called "methodological development". Digital recording, surveying with total stations, is still in its essentials the same as using pen and paper, i.e. the same methodological idea differing in technical application. Computerization has enabled us to make our plot charts within minutes rather than days, handle and cross-reference larger amounts of data without going balmy, and so forth. Of course this rapid technological development will have repercussions on our ontology. Kristian Kristiansen points out three expanding fields of 
new knowledge: "the power of Big Data", "the methodological power of quantification and modelling" and "the theoretical power of new knowledge". Perhaps it is the intersection between quantitative and qualitative production of knowledge that ought to be of interest and elucidated if we want to identify a "new paradigm".

Concerning the power of Big Data and the methodological power of quantification and modelling I have only second-hand knowledge. When asked, my colleagues are much exited, supporting Kristian Kristiansen's statement about a new prehistory. In this case my ignorance is interesting. I hope it says more about our professional division of labour than about me. Obviously these large sweeps, spanning vast areas, long time spans and whole cultures, are not common within the field of medieval/historical archaeology. One might wonder why. We are certainly used to handling large amounts of complex data, and there ought to be some heritage from the French Annales school with its attempts at histoire totale. Is it self-imposed problems in approaching "cultures" in early historical times, not looking for different sets of connections and interrelations, that shows us to be still subordinate to the written sources and "established history"? Are we afraid of getting tangled up in the present political turmoil of nationalistic and regionalist agendas? We clearly have a thing or two to learn here from the prehistorians, so yes, I think there is reason for some mild excitement here.

My reading of Kristian Kristiansen's text is that the theoretical side is presented as an outcome of the technical developments (actually being able to handle "big data"), and more particularly what Kristian Kristiansen describes as "the third scientific revolution in archaeology".

It is the possible, future, potential of the advances in genetics, DNA and strontium analyses that are closest to Kristian Kristiansen's heart: "The A-DNA and strontium revolution redefines human origins, health and mobility, and establishes $a$ new prehistory" (my emphasis). This is of course interesting; migration is, for very different reasons, being placed high on the contemporary political agenda, the question being how we formulate this possible new knowledge.

On the plus side of things it shows the enormous mobility over time. In short, we are all so mixed up that all contemporary populist attempts at a "Balkanization" based on "origins" will finally be seen to be as futile and stupid as they really seem. Kristian Kristiansen holds out a small warning finger about "the dark side of the force", every possibility can be misused, making the analogy of the present situation with that of $\mathrm{CI}_{4}$ dating before calibration. Indeed we run the risk of being naïve, and political idiots initially by uncritical and unreflecting adaptation of these advantages simply because they are there and are "new". That is, however, another discussion. 
I do agree with Kristian Kristiansen that the present situation calls for increasing integration between different fields of knowledge, not only between science and archaeology, but also between archaeology and other humanities, to flag a hobbyhorse of mine. This involves a reformulation and renegotiation of the relationships between disciplines. We all know of "inter-disciplinary" work in reality being "parallel-disciplinary". If these later scientific and theoretical developments, whether paradigmatic or not, are to change archaeology I believe we have to rethink not only theories, questions and techniques, but also organization and the whole order of the discourse.

Kristian Kristiansen also asks if we are going "towards a new public role for archaeological and historical research". "In short: it demands a stronger public engagement by archaeologists, scientists and humanists, perhaps to a degree we are not used to." I fully agree, since archaeology to a large degree tries to stay out of contemporary politics (there are obvious historical reasons for this). A new public role being necessary is beyond doubt, but does also require a "rethink" and reorganization of the whole shaboom. We are, as Kristian Kristiansen points out, facing a new set of challenges, forcing us to take a more explicit place in the fields of politics. This is perhaps more discussed within the field of "rescue archaeology", being a public function and, at least in theory, in closer interaction with different segments of society and politics. But even here we are quite comfortable outside the fields of contemporary politics, meaning we do not act upon those fields. However the fields of contemporary politics constantly act upon us, and at the moment not in a very constructive way if we want a stronger public engagement. Kristian Kristiansen is rather optimistic about the future (i.e. the present). I am rather more worried, looking at the deteriorating conditions for the "archaeological production line", so to speak. The introduction of competitive archaeology on an immature "market" is already having an effect on the production of data. A "re-instrumental" archaeology is producing smaller quantities of data of a slowly decreasing quality. The fields of contemporary politics also act upon the academic sphere in a way that in the end will restrict necessary development (Högberg 20I3) and hamper the way towards a new paradigm.

\section{REFERENCES}

Högberg, A. 20I3. Mångfaldsfrågor i kulturmiljövården: Tankar, kunskaper och processer 2002-20I2. Lund: Nordic Academic Press. 